\title{
MUSCLE INJURY - PHYSIOPATHOLOGY, DIAGNOSIS, TREATMENT AND CLINICAL PRESENTATION
}

Tiago Lazzaretti Fernandes ${ }^{1}$, André Pedrinelli ${ }^{2}$, Arnaldo José Hernandez ${ }^{3}$

\begin{abstract}
Skeletal muscle tissue has the largest mass in the human body, accounting for $45 \%$ of the total weight. Muscle injuries can be caused by bruising, stretching or laceration. The current classification divides such injuries into mild, moderate and severe. The signs and symptoms of grade I lesions are edema and discomfort; grade II, loss of function, gaps and possible ecchymosis; and grade III, complete rupture, severe pain and extensive hematoma. The diagnosis can be confirmed by: ultrasound, which is dynamic and cheap, but examiner dependent; and tomogra-
\end{abstract}

\section{INTRODUCTION}

Muscle injuries are the most frequent cause of physical incapacity in sports practice. It has been estimated that 30 to $50 \%$ of all sports-related injuries are caused by soft-tissue lesions ${ }^{(1)}$.

Although nonsurgical treatment results in a good prognosis for most athletes with muscle injuries, the consequences of treatment failure may be dramatic, postponing the return to physical activity for weeks or even months ${ }^{(2)}$. Knowledge of certain basic principles of the regeneration and repair mechanisms of skeletal muscles may help to avoid imminent hazards and accelerate the return to sport.

\section{Anatomy and biomechanics}

Muscle fibers generally originate in a bone or in dense connective tissue and insert in another bone through a tendon insertion. phy or magnetic resonance, which gives better anatomical definition, but is static. Initial phase of the treatment can be summarized as the "PRICE" protocol. NSAIDs, ultrasound therapy, strengthening and stretching after the initial phase and range of motion without pain are used in clinical treatment. On the other hand, surgery has precise indications: hematoma drainage and muscle-tendon reinsertion and reinforcement.

Keywords - Muscle, Skeletal/physiopathology; Muscle, Skeletal/injury; Muscle, Skeletal/surgery; Regeneration.

There are muscles that traverse one or more joints to generate movement. Muscles with a tonic or postural function are generally wide, planar and located at a single joint, with a low contraction velocity and a capacity to generate and maintain large contractile force. They are generally located in deeper compartments.

Muscles involving two joints have greater contraction velocity and greater capacity to change length, but less capacity to withstand tension. They are generally located in superficial compartments.

With regard to shape, fusiform muscles allow greater range of motion, while pennate muscles have greater contractile strength.

Fiber length is an important determinant of the quantity of contraction possible in a muscle. Since myofibrils generally present oblique distribution within a muscle belly, they are generally shorter than the total length of the muscle.

1 - Master's Student in the Department of Orthopedics and Traumatology, University of São Paulo Medical School; Collaborator in the FIFA Medical Excellence Center.

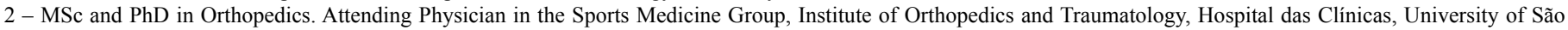
Paulo Medical School; Coordinator of the FIFA Medical Excellence Center.

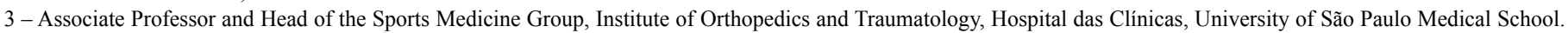

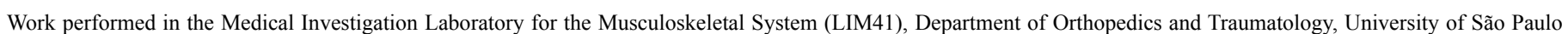

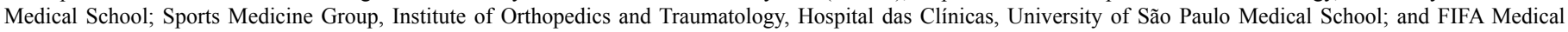
Excellence Center.

Correspondence: Rua Dr. Ovídio Pires de Campos, 333, $2^{\circ}$ andar (LEM) - 05403-010 - São Paulo, SP, Brasil. E-mail: Tiago.lazzaretti@usp.br

Work received for publication: November 20, 2010; accepted for publication: December 23, 2010. 


\section{Injury mechanisms}

Muscle injuries can be caused by bruising, spraining or laceration. More than $90 \%$ of all sports-related injuries are bruises or sprains ${ }^{(3)}$. On the other hand, muscle lacerations are the least frequent injuries resulting from sports.

The tensile force exerted on a muscle may lead to excessive stretching of the muscle fibers and consequently a tear close to the muscle-tendon junction. Muscle sprains are typically observed in the superficial muscles that work by traversing two joints, such as the rectus femoris, semitendinosus and gastrocnemius muscles.

\section{Classification}

The current classification for muscle injuries separates them into mild, moderate and severe according to the clinical features presented ${ }^{(2)}$.

Mild sprains and bruises (grade I) are injuries affecting only some of the muscle fibers, with slight edema and discomfort, accompanied by little or no loss of strength or limitation of movements. It is not possible to palpate any muscle defect during muscle contraction. Although the pain does not cause any significant functional incapacity, it is not recommendable for the athlete to continue with activities because of the great risk that the extent of the injury will increase ${ }^{(4)}$.

Moderate sprains and bruises (grade II) cause greater damage to the muscle, with evident loss of function (ability to contract). It is possible to palpate a small muscle defect or gap at the injury site, and a slight local hematoma is formed with possible ecchymosis, within two to three days. Evolution to healing usually takes two to three weeks and, after around one month, the patient can return to physical activity slowly and carefully ${ }^{(4)}$.

Injuries extending across the entire cross-section of the muscle that result in virtually complete loss of muscle function and intense pain are classified as severe sprains or bruises (grade III). There is evident failure of the muscle structure and the ecchymosis tends to be extensive, often located at a distance from the tear site. The time taken for such injuries to heal ranges from four to six weeks. This type of injury requires intense rehabilitation for long periods (up to three or four months). Such patients may continue to have some degree of pain for months after the occurrence and treatment of the injury ${ }^{(4)}$.

\section{PHYSIOPATHOLOGY}

What distinguishes the healing of muscle injuries from bone healing is that in muscles there is a repair process, while in bone tissue there is a regeneration process.

Healing of skeletal muscles follows a constant order, without significant changes according to the cause (bruising, spraining or laceration).

Three phases have been identified in this process: destruction, repair and remodeling. The last two of these phases (repair and remodeling) overlap and are closely interrelated.

Phase 1: consists of destruction and is characterized by tearing and subsequent necrosis of myofibrils, formation of a hematoma in the space created in the torn muscle and proliferation of inflammatory cells.

Phase 2: consists of repair and remodeling, with phagocytosis of the necrotic tissue, regeneration of the myofibrils and concomitant production of connective scar tissue, along with neoformation of vessels and neural growth.

Phase 3: consists of remodeling, with maturation of the regenerated myofibrils, contraction and reorganization of the scar tissue and recovery of muscle functional capacity.

Since the myofibrils are fusiform and very long, there is an imminent risk that necrosis starting at the injury site will extend along the whole length of the fiber. However, there is a specific structure called the contraction band, consisting of condensed cytoskeletal material, which acts as a "firewall system"(5) (Figure 1).

As the destruction phase diminishes, the repair of the muscle injury starts with two simultaneous processes that compete with each other: regeneration of the torn myofibrils and formation of connective scar tissue. Balanced progression these processes is

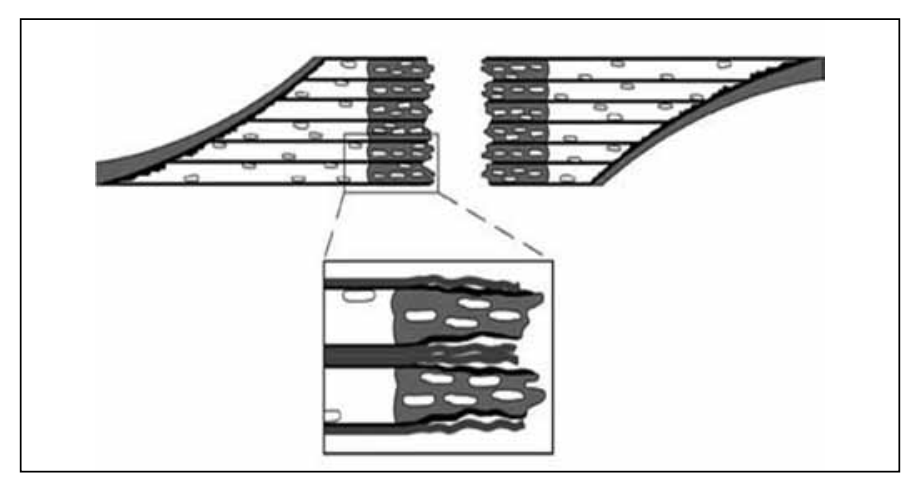

Figure 1. Constriction band of the "firewall system".

Source: Modified from: Jarvinen TA, Jarvinen TL, Kaariainen M et al. Muscle injuries: biology and treatment. Am J Sports Med. 2005; 33:745-64. 
a prerequisite for excellent recovery of the contractile function of the muscle ${ }^{(5)}$.

Although the myofibrils are generically considered to be non-mitotic, the regenerative capacity of skeletal muscles is ensured by an intrinsic mechanism that restores the injured contractile apparatus. During embryonic development, a reserve pool of undifferentiated cells called satellite cells is stored below the basal lamina of each myofibril. In response to a lesion, these cells firstly proliferate, then differentiate into myofibrils and finally join with each other to form multinucleated myotubules ${ }^{(6)}$.

With time, the scar that forms diminished in size, leading the edges of the injury to adhere to each other better. However, it is not known whether the transsection of the myofibrils on opposite sides of the scar will definitively fuse with each other, or whether a septum of connective tissue will form between them ${ }^{(7)}$.

Immediately after the muscle injury, the gap formed by the tear in the muscle fibers is filled by a hematoma. Within the first day, inflammatory cells (including phagocytes) invade the hematoma and start to organize the coagulum ${ }^{(8)}$.

The fibrin derived from blood and the fibronectin intercalate to form granulation tissue, which constitutes an initial frame for anchoring recruited fibroblasts to the site ${ }^{(5)}$. Most importantly, this newly formed tissue provides the property of initial tension to resist the contractions that are applied against it.

Around 10 days after the traumatic event, the maturation of the scar reaches a point at which it is no longer the most fragile part of the muscle injury ${ }^{(9)}$.

Although most musculoskeletal injuries cure without formation of incapacitating fibrous scar tissue, the proliferation of fibroblasts may be excessive, thus resulting in formation of dense scar tissue within the muscle lesion.

One process that is vital for regenerating the injured muscle is the vascularization. Restoration of the vascular supply is the first sign of regeneration, and this is a prerequisite for subsequent morphological and functional recovery ${ }^{(10)}$.

\section{DIAGNOSIS}

Diagnosing the muscle injury begins with obtaining a detailed clinical history of the trauma, followed by a physical examination with inspection and palpa- tion of the muscles involved, along with function tests with and without external resistance ${ }^{(11)}$. The diagnosis is easy when a typical history of muscle bruising is accompanied by evident edema or ecchymosis distal to the injury (Figure 2).

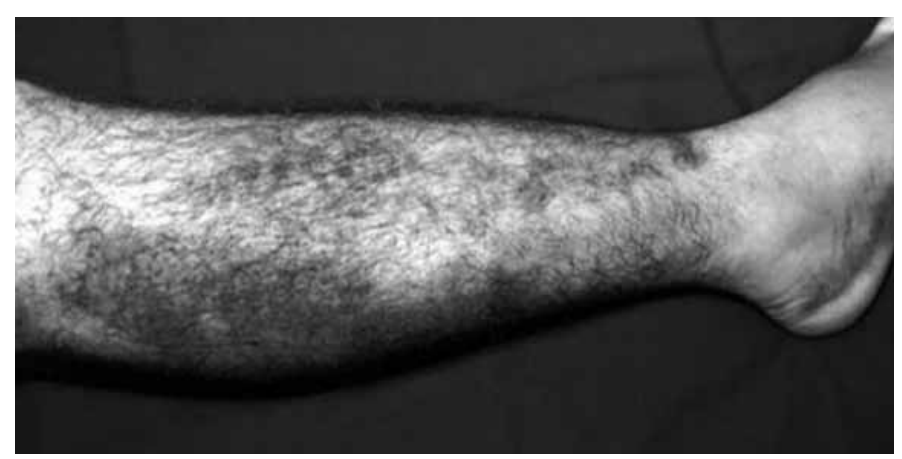

Figure 2. Muscle bruising and ecchymosis on the right. Source: IOT HC-FMUSP, 2008.

\section{Complementary examinations}

Small surface hematomas and those that are deep may be difficult to identify. Imaging examinations such as ultrasound, computed tomography and magnetic resonance provide useful information for investigating and defining the lesion more precisely.

Ultrasound (Figure 3) is traditionally considered to be the method of choice for diagnosing muscle injuries, given that it is a relatively cheap imaging method and enables dynamic assessment of the muscle contraction and tear. It has the disadvantage of being examiner-dependent.

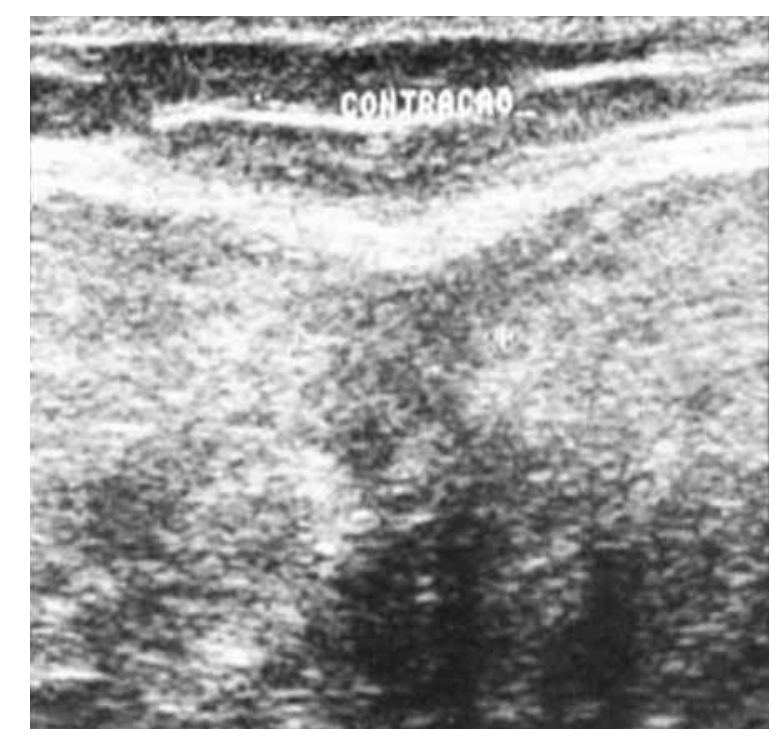

Figure 3 - Ultrasound on the healing constriction band, with muscle contraction.

Source: Outpatient Service, IOT HC-FMUSP, 2008. 
Magnetic resonance imaging (Figure 4) has replaced ultrasound for evaluating many musculoskeletal diseases. It has good sensitivity for edema, for calculating the size of the hematoma and for evaluating muscle-tendon deinsertions. However, like tomography, it is a static examination.

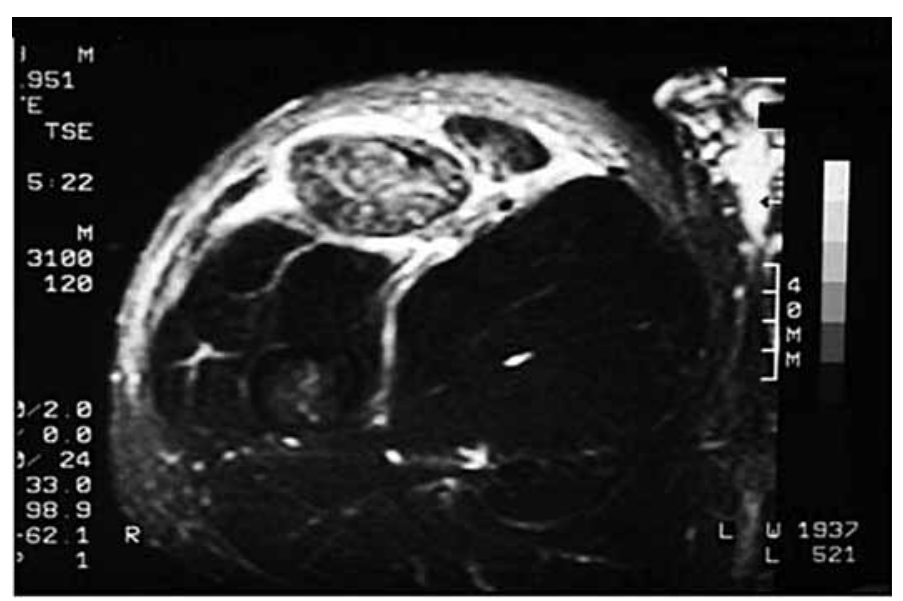

Figure 4 - Magnetic resonance imaging on intra and extracompartment muscle injury. Personal files, 2008.

\section{TREATMENT}

The current principles of muscle injury treatment lack a solid scientific basis.

Early mobilization induces an increase in local vascularization in the area of the lesion, better regeneration of the muscle fibers and better parallelism of orientation of the regenerated myofibrils, in relation to movement restrictions ${ }^{(12)}$. However, renewed tearing at the original site of the trauma is common if active mobilization is started immediately after the injury ${ }^{(13)}$.

A short period of immobilization using firm adhesive dressings or the like is recommended. This period of rest allows the scar tissue to reconnect the muscle failure ${ }^{(3)}$.

The patient should use a pair of crutches in cases of muscle injuries to the lower limbs that are more severe, especially over the first three to seven days.

\section{Acute phase}

The immediate treatment for injuries to skeletal muscles or any soft tissue is known as the PRICE principle (Protection, Rest, Ice, Compression and Elevation). The justification for using the PRICE principle is very practical, given that the five measures are all about minimizing the bleeding at the injury site ${ }^{(11)}$.
Putting the injured limb at rest immediately after the trauma prevents muscle retraction later on, or formation of a larger muscle gap, through reducing the size of the hematoma and subsequently the size of the connective scar tissue. Regard the use of ice, it has been shown that early use of cryotherapy is associated with a significantly smaller hematoma in the gap in the torn muscle fibers, with less inflammation and accelerated regeneration $^{(14)}$.

From the current knowledge, a combination of use of ice and compression over periods of 15 to 20 minutes, with repetitions at intervals of 30 to 60 minutes, is recommended. This type of protocol has been shown to result in a decline in intramuscular temperature of $3^{\circ}$ to $7^{\circ} \mathrm{C}$ and a $50 \%$ reduction in intramuscular blood flow ${ }^{(15)}$.

Finally, elevation of the limb above the level of the heart results in diminished hydrostatic pressure, thus reducing the accumulation of liquid in the interstitial space.

\section{Medication}

There are few controlled studies using nonsteroidal anti-inflammatory drugs (NSAIDs) or glucocorticoids for treating muscle lesions in humans. O'Grady reported that, over the short term, use of anti-inflammatory drugs for treating in situ necrosis (the mildest type of muscle injury) resulted in a transitory improvement in recovery from muscle injuries induced by exercise ${ }^{(16)}$. Despite the lack of evidence, the effects of NSAIDs have been well documented. Järvinen highlighted that using these drugs for a short period during the early stage of the recovery diminished the inflammatory reaction of cells, without side effects on the healing process, tensile strength or muscle contraction ability.

Furthermore, NSAIDs do not retard the activated ability of satellite cells to proliferate or form myotubules $^{(17)}$. Nevertheless, chronic use seems to be prejudicial in the eccentric contraction model for sprain injuries, as discussed by Mishra et $\mathrm{al}^{(18)}$.

With regard to the use of glucocorticoids, delays in elimination of the hematoma and necrotic tissue, delays in the regeneration process and decreased biomechanical strength in the injured muscle have been reported ${ }^{(19)}$. 


\section{Treatment after the acute phase}

1. Isometric training (i.e. muscle contraction in which the length of the muscle remains constant and the tension changes) can be started without using weights and then adding weights later on. Special attention should be paid to ensure that all the isometric exercises are done without pain.

2. Isotonic training (i.e. muscle contraction in which the size of the muscle changes and the tension is maintained) can be started after it becomes possible to do isometric training painlessly with a resistance load. 3. Isokinetic exercises with a minimal load can be started after it becomes possible to do the above two exercises painlessly (Figure 5).

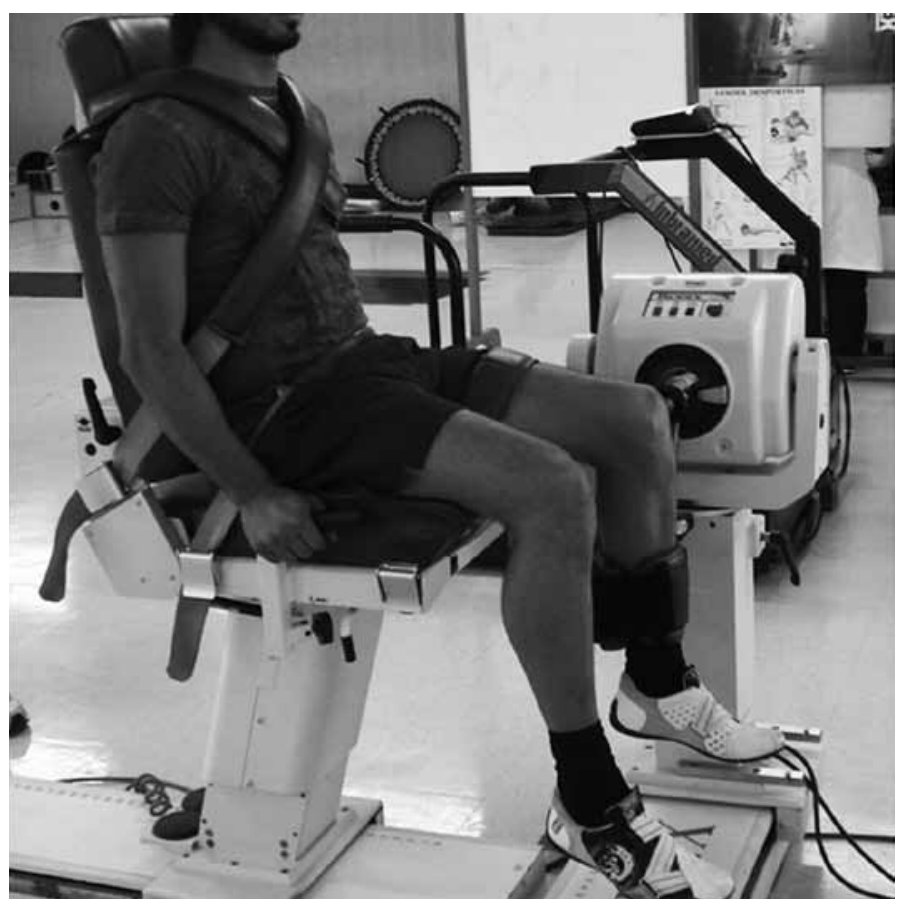

Figure 5 - Isokinetic exercise on left knee.

Source: Movement Study Laboratory (LEM), IOT HC-FMUSP, 2008.

Local application of heat or "contrast therapy" (hot and cold) may be of value, accompanied by careful passive and active stretching of the affected muscle. It is emphasized that any rehabilitation activity should be started with an adequate warm-up for the injured muscle ${ }^{(20)}$.

Another reason for stretching is to distend the mature scar tissue during the phase when it is still plastic. Stretching of the scar without pain can be acquired through gradual strain, starting with applications of 10 to 15 seconds and then progressing to periods of up to one minute.
However, if the symptoms caused by the lesion have not improved by three to five days after the trauma, the possibility that there is an intramuscular hematoma or extensive damaged tissue should be considered, and this will require special attention. Puncture or aspiration of the hematoma may be necessary.

\section{Ultrasound}

Therapeutic ultrasound is widely recommended and used for treating muscle injuries, although the scientific evidence regarding its effectiveness is only vague $^{(21)}$. The fact that ultrasound produces micromassages caused by the high-frequency waves seems to have a pain relief function.

\section{Surgical treatment}

There are precise indications of situations in which surgical intervention is needed. These indications include cases of large intramuscular hematomas, complete lesions or tears (grade III) with little or no associated agonist musculature and partial lesions in which more than half of the muscle is torn ${ }^{(22,23)}$.

Surgical intervention may also be considered if the patient complains of persistent pain on extension for more than four to six months, particularly if there is a deficit of extension. In the latter case in particular, it should be suspected that adhesion of scar tissue has occurred, thereby restricting muscle movement at the injury site.

After the surgical repair has been performed, the muscle should be protected by means of an elastic bandage around the limb, in order to promote relative immobility and compression. The duration of the immobilization naturally depends on the severity of the trauma. Patients with complete rears of the quadriceps or gastrocnemius muscles are instructed not to put any weight on the limb for at least four weeks.

If the gap or muscle failure is exceptionally wide, the denervated portion may generate a permanent neurological deficit and consequent muscled atrophy ${ }^{(9)}$. Surgical repair under these circumstances increases the chance of reinnervation and the development of thick scar tissue may be avoided.

\section{New perspectives}

Therapeutic use of growth factors and gene therapy, separately or in combination, and application of stem cells are the latest and most promising therapeutic options that exist. However, so far, there has been 
little scientific validation for intensifying their use for treating musculoskeletal injuries.

Growth factors and cytokines are potent mitogenic activators for very many cells, including MPC cells during the regeneration of injured muscle cells ${ }^{(24)}$. Therefore, these are promising therapeutic options for assisting in recovering the skeletal musculature.

With regard to stem cells, it has recently been shown that in response to injury, not only specific tissue cells but also non-muscle stem cells participate in the repair process ${ }^{(25)}$.

The first steps towards gene therapy have already been taken. Future studies will demonstrate the areas within which gene therapy will be able to turn into reality the current expectations relating to treatment of muscle trauma.

\section{CLINICAL PRESENTATION}

\section{Quadriceps muscle injury}

Distal lesions of the quadriceps are uncommon injuries and occur most often in individuals over 40 years of age ${ }^{(26)}$. Such injuries may occur through direct trauma, but they are classically reported as forced eccentric contraction in a position of slight flexion of the lower limb in situations in which individuals attempt to restore their balance at the time of a fall.

Spontaneous tears and bilateral tears have been described in athletes with systemic metabolic disorders and in cases of use of steroids ${ }^{(27)}$.

The diagnosis of a tear is based on the clinical findings. After a fall with the knees flexed, patients typically present acute pain above the patella and incapability to remain standing upright unaided.

During the physical examination, such patients are unable to actively extend the knee and there is often a palpable interval above the patella, known as the "sulcus sign" or gap test. They are capable of actively flexing the knee and have full passive flexion and extension of the knee.

Simple radiography is an inexpensive tool for diagnosing tears. Although it does not show any specific abnormality in the lesion, it shows indirect signs of the tear. Soft-tissue edema, joint effusion, calcification, quadriceps tear shadow and low patella are all indirect signs seen on simple radiographs ${ }^{(28)}$.

Like simple radiography, ultrasound is an inexpenRev Bras Ortop. 2011;46(3):247-55 sive method for diagnosing muscle lesions. Magnetic resonance imaging is particularly useful for better viewing and for precisely defining the location and extent of the lesion and the anatomical details for the preoperative workup (Figure 6).

For complete muscle tears, the treatment is surgical. Early surgical treatment in these cases is associated with better functional results ${ }^{(29)}$ (Figure 7 ). On the other hand, delay in carrying out the surgical repair is associated with prolonged periods of physiotherapy, inadequate flexion and loss of full extension of the $\mathrm{knee}^{(29)}$. After the surgical repair, patients remain with the knee immobilized for four to six weeks.
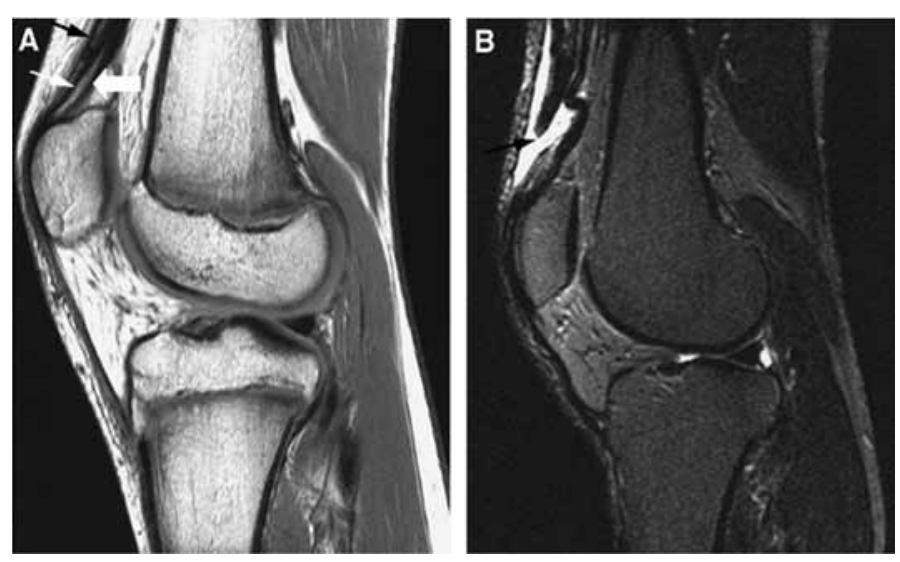

Figure 6 - Magnetic resonance imaging in sagittal plane with T1 weighting $(A)$ and T2 weighting $(B)$, showing quadriceps tendon injury. Source: Modified from: Armfield DR et al. Sports-related muscle injury in the lower extremity. Clin Sports Med. 2006 25(4):803-42.

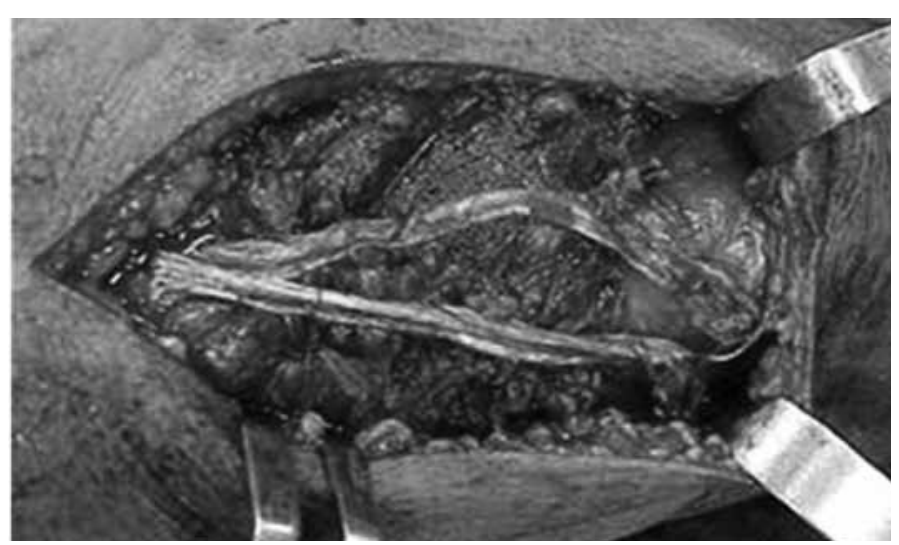

Figure 7 - Open repair on quadriceps muscle injury, with reinforcement of the tendon of the semitendinosus muscle.

Source: IOT HC-FMUSP, 2008.

\section{Hamstring muscle injuries}

The hamstring muscles are the least stretched muscles of the lower limb and, for this reason, they are more easily injured during eccentric muscle contraction 
The severity of the injury is generally neglected, especially during the acute phase. Hamstring sprains are the commonest injury among athletes ${ }^{(30)}$.

These injuries are usually diagnosed from a high degree of clinical suspicion and careful clinical examination. Magnetic resonance imaging is valuable for differentiating between complete and incomplete lesions and for planning the treatment (Figure 8).

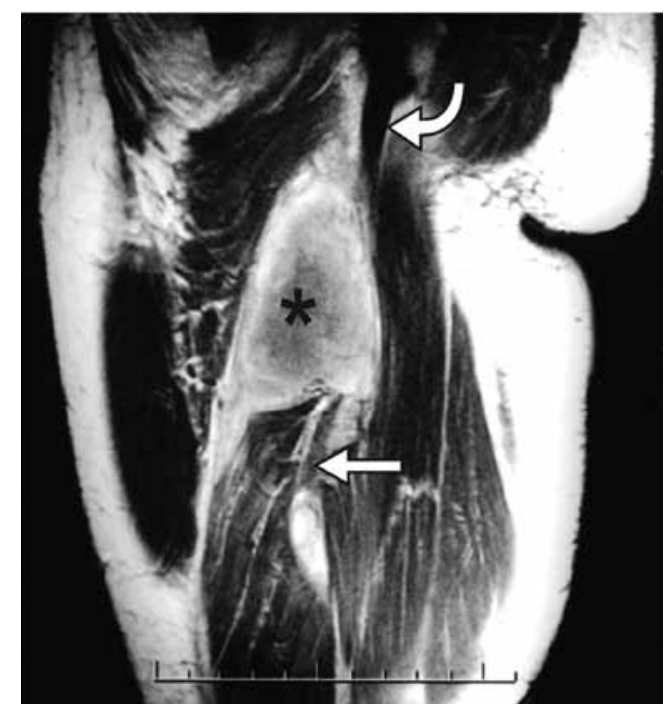

Figure 8- Magnetic resonance imaging on the thigh of an athlete with completely torn hamstring muscles and hematoma.

Source: Modified from: Koulouris $\mathrm{G}$ et al. Hamstring muscle complex: an imaging review. Radiographics. 2005 25(3):571-86.

Complete tearing of the hamstring muscles proximally to their origin is rare. The management for hamstring cases ranges from conservative treatment with immobilization in flexion to surgical repair at a later time. Although surgical repair at a later time may present good results, early repair enables faster functional rehabilitation and avoids the potential neurological symptom of gluteal sciatica.

\section{Adductor musculature injury}

The adductor muscle group acts in conjunction with the low abdominal muscles to stabilize the pelvis during activities of the lower limbs. Athletes who participate in activities that require repeated kicks, spurts or frequent changes of direction have greater incidence of chronic pain in the region of the adductors ${ }^{(31)}$. There is evidence that athletes with weakness of the adductor muscles, imbalance between adductors and abductors (Figure 9) and diminished hip range of motion are more likely to acquire pubalgia during the playing season $^{(32)}$.

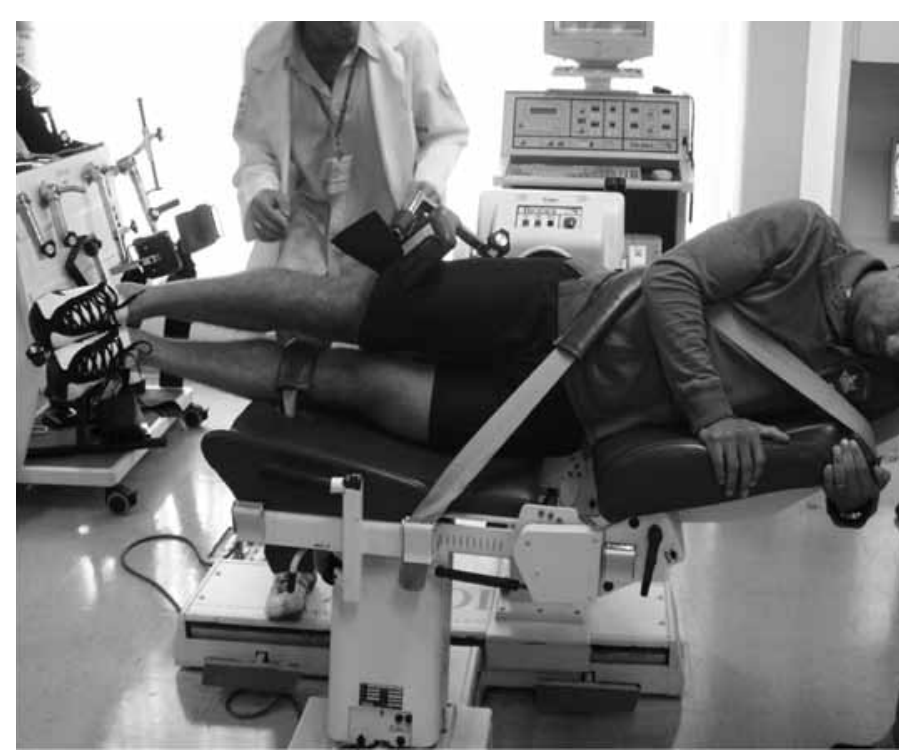

Figure 9 - Isokinetic evaluation on adductor and abductor muscles. Source: Movement Study Laboratory (LEM), IOT HC FMUSP, 2009.

The patients typically present discomfort in the region of the groin or medial pain in the thigh, and a triggering factor may or may not be reported. On physical examination, pain is presented on palpation, with focal edema along the adductor muscles, diminished muscle strength and pain on performing hip adduction resistance exercises.

The diagnosis can be made from the findings of the physical examination. Nevertheless, magnetic resonance imaging with contrast may be useful for confirming the diagnosis or making a differential diagnosis between pubic osteitis and sports hernia ${ }^{(33)}$.

The initial treatment is conservative. Infiltration of the enthesis of the long adductor may be useful for refractory treatment. In cases of acute tears, open surgical repair with placement of anchors and suturing has been described, with good results ${ }^{(34)}$.

Patients may return to their sport after returning to their previous pattern of hip strength and range of motion, and after resolution of the painful state. Because predisposition to adductor injury is caused by muscle imbalance, attention should be paid to strengthening the musculature in order to prevent new lesions.

\section{Gastrocnemius muscle injuries}

Like the hamstrings and quadriceps, the gastrocnemius has a propensity to injury because it traverses two joints.

The medial head of the gastrocnemius is more 
commonly injured than is the lateral head, given that it is more active ${ }^{(35)}$. Deep vein thrombosis may be associated, or it may be a differential diagnosis for pain in the calf muscle, along with thrombophlebitis ${ }^{(36)}$.

The term "tennis leg" has been used to describe pain and injury in the calf. This condition is attributed to the serving move in tennis, in which there is complete extension of the knee together with abrupt dorsiflexion of the ankle, thus causing maximum stretching of the calf. However, this injury has also been described in young athletes during periods of strenuous exercises, like in basketball, running and muscle training ${ }^{(37)}$.

The pain appears suddenly, with focal edema and ecchymosis of the calf. Classically, tennis leg is described as an injury of the distal muscle-tendon junction, although proximal lesions may occur.

Because of the superficial nature of the injury, ultrasound evaluations are reliable. This easily makes it possible to rule out the presence of deep vein thrombosis and implement image-guided aspiration of fluid accumulations.

The treatment for most gastrocnemius lesions is conservative. Surgery occasionally needs to be un- dertaken in order to drain hematomas, repair grade III lesions or perform compartmental decompression in cases of compartmental syndrome.

\section{FINAL REMARKS}

Comprehension of the physiopathological mechanisms that regulate muscle repair and its adaptation to physical training is essential for professionals intending to treat such patients. It is the basis for developing methods for injury prevention and for adequate treatment and rehabilitation of injuries that have occurred.

The appropriate length of resting time before returning to specific training for a sport needs to be respected. The decision on when to return can be based on two simple and non-burdensome measurements: ability to stretch the injured muscle as much as on the healthy contralateral side; and absence of pain in the injured muscle when making basic movements.

When patients report that they have reached this point in their recovery, permission to gradually start doing specific exercises for their sport is assured. Nevertheless, it always needs to be emphasized that the final phase of the rehabilitation should be conducted under supervision by a capacitated professional.

\section{REFERENCES}

1. Herring SA, Nilson KL. Introduction to overuse injuries. Clin Sports Med. 1987;6(2):225-39.

2. Pedrinelli A, Fernandes TL, Thiele E, Teixeira WJ. Lesão muscular - ciências básicas, fisiopatologia, diagnóstico e tratamento. In: Alves Júnior WM, Fernandes TD, editors. Programa de atualização em traumatologia e ortopedia (PROATO). Porto Alegre: Artmed; 2006. p. 10, 32.

3. Järvinen MJ, Lehto MU. The effects of early mobilisation and immobilisation on the healing process following muscle injuries. Sports Med (Auckland, N.Z.). 1993;15(2):78-89.

4. Hernandez AJ. Distensões e rupturas musculares. In: Camanho GL, editor. Patologia do joelho. São Paulo: Sarvier; 1996. p. 132-8.

5. Hurme T, Kalimo H, Lehto M, Järvinen M. Healing of skeletal muscle injury: an ultrastructural and immunohistochemical study. Med Sci Sports Exerc. 1991;23(7):801-10

6. Rantanen J, Hurme T, Lukka R, Heino J, Kalimo H. Satellite cell proliferation and the expression of myogenin and desmin in regenerating skeletal muscle: evidence for two different populations of satellite cells. Lab Invest. 1995;72(3):341-7.

7. Aärimaa V, Kääriäinen M, Vaittinen S, Tanner J, Järvinen T, Best T, et al. Restoration of myofiber continuity after transection injury in the rat soleus. Neuromuscul Disord. 2004;14(7):421-8.
8. Cannon JG, St Pierre BA. Cytokines in exertion-induced skeletal muscle injury. Mol Cell Biochem. 1998;179(1-2):159-67.

9. Kääriäinen $M$, Kääriäinen J, Järvinen $T L$, Sievänen $H$, Kalimo $H$, Järvinen $M$. Correlation between biomechanical and structural changes during the regeneration of skeletal muscle after laceration injury. J Orthop Res. 1998;16(2):197-206.

10. Järvinen M. Healing of a crush injury in rat striated muscle. 3. A micro-angiographical study of the effect of early mobilization and immobilization on capillary ingrowth. Acta Pathol Microbiol Scand A. 1976;84(1):85-94.

11. Fernandes TL, Pedrinelli A, Hernandez AJ. Dor na coxa e na perna. In: Nobrega A, editor. Manual de medicina do esporte. São Paulo:Atheneu; 2009. p. 140-1.

12. Järvinen $M$. Healing of a crush injury in rat striated muscle. 2. A histological study of the effect of early mobilization and immobilization on the repair processes. Acta Pathol Microbiol Scand A. 1975;83(3):269-82.

13. Lehto M, Duance VC, Restall D. Collagen and fibronectin in a healing skeletal muscle injury. An immunohistological study of the effects of physical activity on the repair of injured gastrocnemius muscle in the rat. J Bone Joint Surg Br. 1985;67(5):820-8.

14. Hurme T, Rantanen J, Kaliomo H. Effects of early cryotherapy in experimental skeletal muscle injury Scand J Med Sci Sports. 1993;3(1):46-51.

15. Thorsson O, Hemdal B, Lilja B, Westlin N. The effect of external pressure on 
intramuscular blood flow at rest and after running. Med Sci Sports Exerc. 1987;19(5):469-73.

16. O'Grady M, Hackney AC, Schneider K, Bossen E, Steinberg K, Douglas JM et al. Diclofenac sodium (Voltaren) reduced exercise-induced injury in human skeletal muscle. Med Sci Sports Exerc. 2000;32(7):1191-6.

17. Thorsson $\mathrm{O}$, Rantanen $\mathrm{J}$, Hurme $\mathrm{T}$, Kalimo $\mathrm{H}$. Effects of nonsteroidal antiinflammatory medication on satellite cell proliferation during muscle regeneration. Am J Sports Med. 26(2):172-6.

18. Mishra DK, Fridén J, Schmitz MC, Lieber RL. Anti-inflammatory medication after muscle injury. A treatment resulting in short-term improvement but subsequent loss of muscle function. J Bone Joint Surg Am. 1995;77(10):1510-9.

19. Beiner JM, JokI P, Cholewicki J, Panjabi MM. The effect of anabolic steroids and corticosteroids on healing of muscle contusion injury. Am J Sports Med. 27(1):2-9.

20. Magnusson SP, Simonsen EB, Aagaard P, Gleim GW, McHugh MP, Kjaer M. Viscoelastic response to repeated static stretching in the human hamstring muscle. Scand J Med Sci Sports. 1995;5(6):342-7.

21. Wilkin LD, Merrick MA, Kirby TE, Devor ST. Influence of therapeutic ultrasound on skeletal muscle regeneration following blunt contusion. Int J Sports Med. 2004;25(1):73-7.

22. Almekinders LC. Results of surgical repair versus splinting of experimentally transected muscle. J Orthop Trauma. 1991;5(2):173-6.

23. Kujala UM, Orava $S$, Järvinen $M$. Hamstring injuries. Current trends in treatment and prevention. [Internet]. Sports Med (Auckland, N.Z.). 1997;23(6):397-404.

24. Best TM, Shehadeh SE, Leverson G, Michel JT, Corr DT, Aeschlimann D. Analysis of changes in mRNA levels of myoblast- and fibroblast-derived gene products in healing skeletal muscle using quantitative reverse transcriptionpolymerase chain reaction. J Orthop Res. 2001;19(4):565-72.

25. LaBarge MA, Blau HM. Biological progression from adult bone marrow to mononucleate muscle stem cell to multinucleate muscle fiber in response to injury. Cell. 2002;111(4):589-601.
26. Siwek CW, Rao JP. Ruptures of the extensor mechanism of the knee joint. J Bone Joint Surg Am. 1981;63(6):932-7.

27. Liow RY, Tavares S. Bilateral rupture of the quadriceps tendon associated with anabolic steroids. Br J Sports Med. 1995;29(2):77-9.

28. Stephens BO, Anderson GV. Simultaneous bilateral quadriceps tendon rupture: a case report and subject review. J Emerg Med. 5(6):481-5.

29. Walker LG, Glick H. Bilateral spontaneous quadriceps tendon ruptures. A case report and review of the literature. Orthop Rev. 1989;18(8):867-71.

30. Blasier RB, Morawa LG. Complete rupture of the hamstring origin from a water skiing injury. Am J Sports Med. 18(4):435-7.

31. Cunningham PM, Brennan D, O'Connell M, MacMahon P, O'Neill P, Eustace S. Patterns of bone and soft-tissue injury at the symphysis pubis in soccer players: observations at MRI. AJR Am J Roentgenol. 2007;188(3):W291-6.

32. Verrall GM, Slavotinek JP, Barnes PG, Esterman A, Oakeshott RD, Spriggins AJ. Hip joint range of motion restriction precedes athletic chronic groin injury. J Sci Med Sport. 2007;10(6):463-6.

33. Schilders E, Bismil Q, Robinson P, O'Connor PJ, Gibbon WW, Talbot JC. Adductor-related groin pain in competitive athletes. Role of adductor enthesis, magnetic resonance imaging, and entheseal pubic cleft injections. J Bone Joint Surg Am. 2007;89(10):2173-8.

34. Vogt S, Ansah P, Imhoff AB. Complete osseous avulsion of the adductor longus muscle: acute repair with three fiberwire suture anchors. Arch Orthop Trauma Surg. 2007;127(8):613-5.

35. Segal RL, Song AW. Nonuniform activity of human calf muscles during an exercise task. Arch Phys Med Rehabil. 2005;86(10):2013-7.

36. Bianchi S, Martinoli C, Abdelwahab IF, Derchi LE, Damiani S. Sonographic evaluation of tears of the gastrocnemius medial head ("tennis leg"). J Ultrasound Med. 1998;17(3):157-62.

37. McClure JG. Gastrocnemius musculotendinous rupture: a condition confused with thrombophlebitis. South Med J. 1984;77(9):1143-5. 